\title{
Reform of internal control system in electric power enterprises under digital wave
}

\author{
Geng Bao ${ }^{1, *}$, Lingle Zhang ${ }^{2}$, MinhuaChen $^{1}$ \\ ${ }^{1}$ Information Center, China Three Gorges Corporation, Beijing, China \\ ${ }^{2}$ Department of Economics, The Engineering\&Technical College of Chengdu University of Technology, Chengdu, China
}

\begin{abstract}
With the advent of the digital era represented by "cloud, big, material, mobile, intelligent" and $5 \mathrm{~g}$, many new concepts and technologies have emerged, which brings both opportunities and challenges to the reform of management system of power enterprises. This paper discusses the internal control system of electric power enterprises, which from the perspective of the reform and construction of internal control system under digital conditions.
\end{abstract}

\section{Introduction}

Facing the competitive pressure brought by the continuous development of market economy, the digital transformation of state-owned enterprises and the threeyear action plan of state-owned enterprises, the reform of enterprise system and mechanism is imperative. For this reason, the state has specially promulgated the document "several opinions on further deepening the reform of electric power system" and issued relevant regulations. That require the reformation of electric power enterprises should take the modern enterprise system as the basics, improve the management system, especially the construction of internal control system, and promote the improvement of management level and competitiveness.

\section{Concept of internal control in electric power enterprises}

"Helping power digital transformation and promoting high-quality development of the industry" is the theme of China Power Development Forum held in Beijing in September 2020. The meeting believes that the development trend of digital transformation of power enterprises, new infrastructure, hydrogen industry and other new energy will have a significant impact on the development and reform of power enterprises during the 14th Five Year Plan period. The construction of global energy Internet, the realization of power production globalization, will be a great significance for China's power enterprises to get out of the dilemma of overproduction. The new strategic of globalization requires Chinese power enterprises to establish a comprehensive risk management system to fully adapt to the diversified market competition.

Through internal coordination, integration, management and control, enterprises can ensure the accuracy of accounting and economic information, and the safety and integrity of internal resources, which we usually call internal control. The implementation of the so-called internal control system of power enterprises means that due to the different division of labor and different responsibilities in the enterprises, it naturally constitutes a kind of restriction. Under this restriction, the methods, means and measures with control ability can be implemented in the enterprise, and they are constantly systematic, standardized and perfected. The content of the paper mainly includes the following five aspects:

First, the internal environment. Organizational structure, management mode, development goal and social responsibility all belong to this category. It has a direct impact on enterprise operation. It also impact the realization of strategic goal and the implementation of internal control, and plays a fundamental role in the construction of internal control system. Second, risk identification. Power enterprises identify and analyze the risks that may affect the enterprise objectives, and control and prevent them. It constitutes the cornerstone of risk management and plays an important role in the internal control system of enterprises. Third, internal control activities. There are internal control activities in all departments, units and the whole process of production and operation in electric power enterprises, which provide guarantee for the operation and management activities of enterprises. Fourth, information communication. Establish a threedimensional network system to meet the needs of information acquisition, confirmation and exchange, so that employees can perform their duties and prepare

*Corresponding author:653855120@qq.com 
financial reports in a relatively fixed form at a specific time. Fifth, internal control supervision requires power companies to strengthen supervision before, during and after the event.

\section{Problems in the internal control system of electric power enterprises}

The status quo of internal control system of China's power enterprises is shown in Figure 1 below

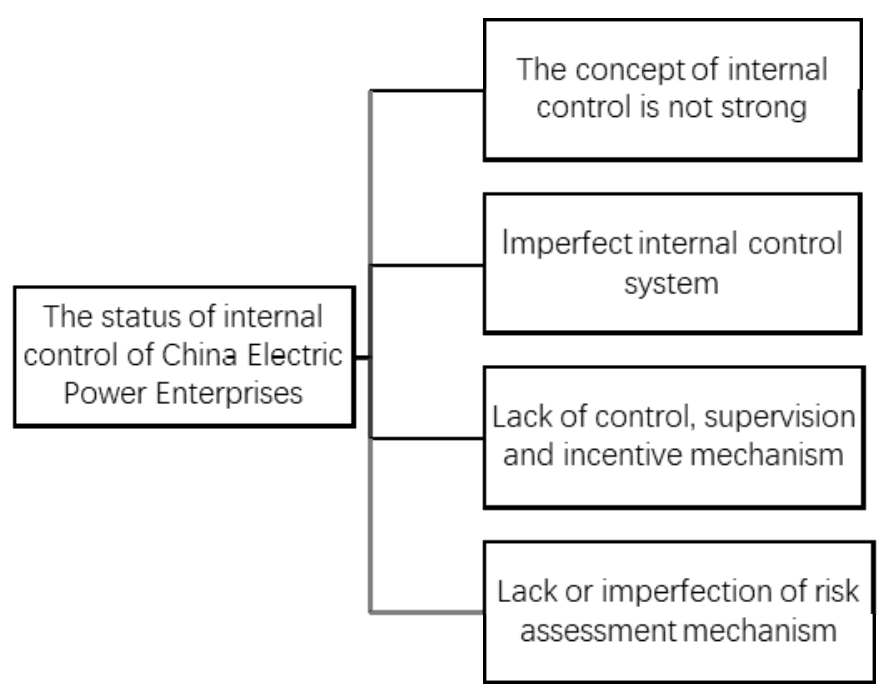

Figure 1 current situation of internal control in China's power enterprises

\subsection{The concept of internal control is not strong}

The electricity relates to the international people's livelihood, so production electric power plays an important role in the development of international economy and people's lives. Because of its particularity, coupled with China's economic system, power enterprises occupy a monopoly position in China. This also directly leads to the relative lack of risk and competition awareness. The key point of the control of the enterprises is to strengthen the financial accounting, but the goal of adapting to the social, economic, sustainable development and long-term development of the management environment is not established. There is no comprehensive and systematic internal control concept, which leads to the lack of continuous, long-term and dynamic internal control.

\subsection{The internal control system is not perfect}

Development and profit are the value of the existence of enterprises and the ultimate goal of all enterprises. So in the process of operation, some power companies pay more attention to enterprise profits than to the construction of internal control system and related systems, which affects the efficiency and sustainable development of enterprises. At present, most power enterprises in China have established a relatively perfect information-based financial system. However, based on the information-based financial system, an intelligent and whole process internal control system is constructed It has not yet been established, resulting in the waste of human, financial, material and other resources.

\subsection{Internal control supervision and incentive mechanism is insufficient}

On the other hand, most power companies in China have established internal control system, but the actual implementation is not in strict accordance with the relevant provisions. The fundamental reason for this situation is that there is no perfect and scientific assessment system and mechanism, and there is no strong internal control supervision, which makes it difficult for internal control to play its role. Moreover, there are many deficiencies in the incentive mechanism of electric power enterprises. For example, there are few incentives for employees in electric power companies. Under the existing total wage system, the enterprise wage system is relatively rigid, which will seriously reduce the learning enthusiasm and work enthusiasm of employees.

\subsection{The risk assessment mechanism is missing or imperfect}

With the development of economy, power enterprises are facing more and more pressure. Faced with a variety of uncertain risk factors in the external market, in order to achieve good development and vision, enterprises must timely assess the risks on the basis of effective management and control. The power enterprises that monopolized the market in the early years. That time they concentrated in the production process and less risky in operation and management. At this stage, the State advocates the strategy of "going out" and "one belt and one way". The external environment of the enterprise has undergone tremendous changes, and the competition has 
intensified, and the power enterprises are threatened. Therefore, it is urgent to establish and improve the risk assessment mechanism.

\section{Suggestions on improving the internal control system of electric power enterprises}

\subsection{Improve internal control and risk awarenes}

As the leader of an enterprise, leaders should have a deep and clear understanding of internal control, understand their important role in the daily operation of the enterprise, and provide support and guarantee from various aspects, such as increasing personnel allocation on human resources, inclining the system establishment, etc. The executor of specific business of the enterprise should carry out operation activities orderly for the enterprise. We must join in the activities of system construction and give full play to their enthusiasm and creativity. In the new external environment, the majority of cadres and staff of power enterprises need to tighten the risk at all times, and deal with the sudden risks faced by the enterprises in operation at any time. By using new information technology, a risk identification and control system based on big data and AI can be established to distinguish and early-warning risks. According to the early warning, the possible risks are controlled. In view of the risk prevention work, the principle of positive and stable should be followed, and the risk assessment system should be improved constantly.

\subsection{Gradually establish and improve the internal control system}

If the internal control want to play a role of behavior restraint and supervision, first we must establish and improve the internal control system. System restriction is the principle of enterprise operation, which requires that the construction of risk management and control system. Control system should base on risk prevention, focus on control, set up the whole business process inspection mechanism, especially for the post effect inspection. Control system should also build a post supervision and evaluation system, and set up a special committee composed of personnel with relevant professional knowledge and experience for the problem of risk specialization, which to sort out the possible risks, carry out regular audit inspection, improve work efficiency. The control system should cover the life cycle management system which based on the information system of project approval, bidding, contract management and budget. To realizes the closed-loop information, intelligent management and control of the whole process of project and assets from procurement to receiving to scrapping.

\subsection{Embedding a big data governance framework in the organization}

The introduction of big data factors has changed the goals, structure and transmission channels of traditional corporate governance. The corporate governance model oriented by interest checks and balances is gradually being replaced by the governance model oriented by information control. Therefore, it is very important to embed big data in corporate governance, and it can adapt to the goals and requirements of corporate governance under big data (Figure2).

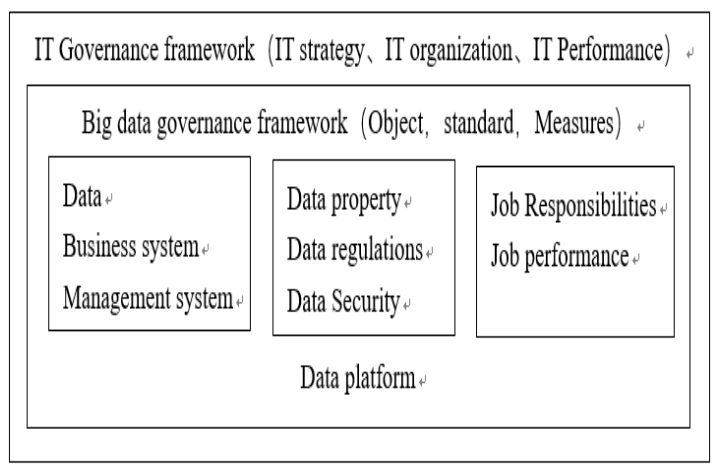

Figure 2 big data governance structure

The governance structure should include three parts. The first is a big data platform, which processes and regulates data from aspects of information integration, information governance, stream computing, accelerators, filters, data warehouses, etc. The second is to process, explore, and apply existing data on this basis. The third is risk visualization query, internal control evaluation system management, etc.

\subsection{Strengthen internal control and supervision}

Electric power companies must, on the premise of upholding the core leadership of the party group, improve their corporate governance structure, and establish an internal supervision mechanism that combines internal audit, internal supervision, and disciplinary inspection. At the same time, it conducts supervision and management, such as regularly reviewing financial reports, reviewing the effectiveness and scientificity of the internal control system. It can also use tenure economic responsibility audit, resignation audit, inspection, and continuous supervision and improvement through special inspections to escort the company's long-term development.

\section{Conclusion}

With the rapid development of digitalization, the more scientific and perfect market economy system, internal control has become an important means for enterprises to strengthen management. It plays a more and more important role in enterprise management. How to establish a set of modern digital technology such as big data, cloud computing and AI, combined with the actual situation of China's power enterprises, with the 
characteristics of China's state-owned enterprises, to adapt to the market economy of modern enterprise intelligent, whole process internal control system, is the goal and direction of the reform and construction of China's power enterprise internal control system.

\section{References}

1. Li cunji. Analysis of internal control management and financial risk prevention of state-owned enterprises [j]. Accounting learning, 2021 (06): 191192

2. Li Yejun. Research on the construction of enterprise internal control system based on information environment $[\mathrm{J}]$. Finance and accounting learning, 2020 (22): 193-194

3. Tang Jin Nian. The construction of financial management and internal control system of Chinese enterprises in the new period [j]. Finance and accounting learning, 2018 (27): 11-12

4. Xiao Heyan. How to strengthen the construction of internal control system in power enterprises [J]. Finance and accounting learning, 2018 (15): $254+$ 256

5. Mao Xiuying. Problems and Countermeasures of internal control in power enterprises [J]. Contemporary economy, 2011 (22) : 41 42. 